\title{
Evaluation of commercial trainer effectiveness based on DEA cross-efficiency model
}

\author{
Yu Fen \\ College of Aeronautical Engineering, Civil Aviation \\ University of China \\ Tianjin, China \\ e-mail: fyu@cauc.edu.cn \\ Liu Li-wen \\ College of Aeronautical Engineering, Civil Aviation \\ University of China \\ Tianjin, China \\ e-mail: 1lwxxu1990@163.com
}

\author{
ZHANG Wei-gang \\ College of Aeronautical Engineering, Civil Aviation \\ University of China \\ Tianjin, China \\ e-mail: wgangzhang@cauc.edu.com
XU Hang
College of Aeronautical Engineering, Civil Aviation
University of China
Tianjin, China
e-mail:643944710@qq.com

\begin{abstract}
In order to evaluate the trainer training effectiveness precisely, DEA cross-efficiency model is used to modify the Masefield - Burdak model by introducing cross efficiency.The trainer training effectiveness model is established again. On calculating evaluation matrixes of the aircraft's Performance indexes, it is normalized by being distributed into benefit-type, and cost-type. Finally, the correctness of this model was verified through the courses of pilot school commercial flight license training with C172S, P2010, DA40 and P2006T.The result is accorded with reality.
\end{abstract}

Key word-Air transportation; The trainer; Flight training; Cross-efficiency model; Training effectiveness evaluation .

\section{INTRODUCTION}

The earliest research on trainer training effectiveness evaluation is about the second generation of jet military trainer cost effectiveness analysis model [1], proposed by Dott Bazzocchi in 1978.In 1990's,Swiss scholars 0. L.P.Masefield and E.A.P.Burdak made revision to it and put forward a method for trainer training effectiveness evaluation, noted Masefield-Burdak model [2].Few studies have been done on training effectiveness by Domestic scholars, they mainly use this model for military trainer's training effectiveness evaluation [3-6].This method is based on multi-index comprehensive evaluation theory, includes three steps: selecting evaluation indexes, determining the weight of each index, and establishing function to calculate the efficiency value of the each trainer based on evaluation indexes and weight coefficient. Because of lacking comprehensive consideration on the relation between input and output indexes of decision making units (evaluation units) ,using multi-index comprehensive evaluation theory merely would reduce the accuracy of evaluation results [7].

Data envelopment analysis (DEA) is a quantity analysis method to evaluate unit of production efficiency, put forward by the famous American operational research expert Charnes. It has some classic models such as $C^{2} R$ and $B C^{2}$ [8]. Academia considers there are some disadvantages in existing DEA modes. The self- assessment multiplier completely relying on selfassessment could not reflect the evaluation results objectively. In response to this problem, Sexton et al put forward cross-efficiency evaluation model based on $C^{2} R$ [9].The method used "self-evaluation" and "peerevaluation" strategy, making up for the shortage of completely relying on self-evaluation .In this way, the evaluation result becomes more objective and credible.

In order to evaluate the trainer training effectiveness precisely, this article uses cross-efficiency evaluation model to modify Masefield-Burdak model by introducing cross-efficiency, and establishes DEA cross-efficiency trainer effectiveness evaluation model. the correctness of this model is verified through a pilot school's commercial single training course. Result shows that it is consistent with Masefield - Burdak model.

\section{MASEFIELD-BURDAK TRAINER TRAINING EFFECTIVENESS EVALUATION MODEL}

Scholars 0. L.P.Masefield and E.A.P.Burdak think that training effectiveness of trainer has some relationship with performance indexes, flight training courses and training time of the courses. The mathematical model [2] is:

$$
T_{E}=S^{\prime} \times W \times F
$$

where:

$T_{E}$ - value of trainer training effectiveness ; $S$ evaluating indexes normalization matrix (associated with the performance index of the plane); $W$ - weight of evaluation indexes to training courses; $F$ - proportion of training courses time.

\section{TRAINING EFFECTIVENESS EVALUATION MODEL BASED ON DEA CROSS- EFFICIENCY MODEL}

\section{A. The DEA cross-efficiency model of evaluation unit}

When evaluating trainer training effectiveness, evaluation indexes could be divided into benefit-type and cost-type. Cost-type indexes should be the smaller the better, benefit-type on the contrary [10]. To DEA, the 
input index should be as small as possible, the greater the output indexes should be better, so we can use cost-type index as input index of evaluation unit, benefit-type index as output index, and then use DEA method to evaluate [11].

Suppose the number of trainer which will be evaluated is $k$ and treat every trainer as a evaluation unit $D M U_{d}(d=1,2, \cdots, k)$.To $D M U_{d}$, its Input/output vector are $X_{d}>0$ and $Y_{d}>0 . X_{d}$ represents the vector of the $d_{t h}$ trainer's cost-type evaluation indexes and $Y_{d}$ represents the vector of the $\mathrm{d}_{\mathrm{th}}$ trainer's benefit-type evaluation indexes. We defines $h_{d}=\frac{U_{d}{ }^{\prime} Y_{d}}{V_{d}{ }^{\prime} X_{d}}$ as the $\mathrm{d}_{\mathrm{th}}$ trainer's efficiency exponent. So using the $h_{d}$ as a target and other trainer's efficiency exponent as constraints, fractional Programming model is as follow:

$$
\begin{array}{ll}
\max & h_{d}=\frac{U_{d}{ }^{\prime} Y_{d}}{V_{d}^{\prime} X_{d}} \\
& \\
\text { s.t. } & \frac{U_{d}^{\prime} Y_{j}}{V_{d}^{\prime} X_{j}} \leq 1 ; \\
& j=1,2, \cdots, k ; \\
& V_{d} \geq 0 ; \\
& U_{d} \geq 0 .
\end{array}
$$

$U_{d} 、 V_{d}$ is as input and output index weight vectors respectively.

We mark the optimal solution of model (2) as $\left(h_{d}^{*}, U_{d}^{*}, V_{d}^{*}\right)$, and the cross-efficiency of $D M U_{d}$ is

$$
E_{d}=\frac{1}{k} \sum_{j=1}^{k} \frac{U_{j}^{* '} Y_{d}}{V_{j}^{* \prime} X_{d}}
$$

\section{B. Introducing cross-efficiency to establish trainer training effectiveness evaluation model}

Using the cross efficiency calculated from formula (3) to modify Masefield - Burdak model, a revised model is:

$$
T_{E}=E \times\left(S^{\prime} \times W \times F\right)
$$

$$
\text { where } E=\operatorname{diag}\left(E_{1}, E_{2}, \cdots, E_{k}\right) \text {. }
$$

The difference between and model (1) is that model (4) has considered the cross efficiency of evaluation unit, making up for the lack of considering the deficiency of the input and output indexes comprehensive relations of the model (1).Using this model to evaluate trainer training effectiveness could make the evaluation results more precisely.

\section{V.CASE ANALYSIS}

We take a pilot school' commercial single-engine training at stage 1 as an example,and select commonly

\section{COMMERCIAL TRAINER TRAINING EFFECTIVENESS EVALUATION}

\section{A. The normalization of evaluation index}

Considering trainer aircraft flight training characteristics ,determined 9 evaluation indexes are: Take-off distance(ground roll), Take-off distance(50 foot obstacle), landing distance(ground roll), landing distance(50-foot obstacle), Maximum rate of climb, Ceiling, Cruise speed of design, Maximum range and Maximum take-off weight. Evaluation indexes should be normalized.

To maximum take-off weight, maximum rate of climb, ceiling, Cruise speed of design and maximum range ,the values can be the greater the better. its greater value could give students more operating margin, so it can be classified as benefit-type index. While restricted by pilot school actual situation, the value of Take-off distance(ground roll), Take-off distance(50 foot obstacle), landing distance(ground roll), landing distance(50-foot obstacle) would be smaller the better, it could be classified as cost-type.

Index normalized method is given below. Suppose the number of trainer which will be evaluated is $k$ and evaluation indexes is $\beta_{j}(j=1, \cdots, n)$.The value of the $i_{t h}(i=1, \cdots, k)$ trainer's evaluation index $\beta_{j}$ is $x_{i j}$ The maximum and minimum of Evaluation index $\beta_{j}$ is $r_{\max }^{j}=\max _{1 \leq i \leq k}\left\{x_{i j}\right\}$ and $r_{\min }^{j}=\min _{1 \leq i \leq k}\left\{x_{i j}\right\}$ respectively. The normalized value uses $s_{i j}$ represent it.

If evaluation index $\beta_{j}$ is benefit-type, then

$$
s_{i j}=\frac{x_{i j}}{r_{\max }^{j}}
$$

If Evaluation index $\beta_{j}$ is cost-type, then

$$
s_{i j}=1-\frac{x_{i j}-r_{\min }^{j}}{r_{\max }^{j}}
$$

For this, the normalized matrix $S=\left(s_{i j}\right)_{n \times k}$ [11] could be obtained.

\section{B. The determination of weight matrix}

Flight training course set by training program.We get the weighting matrix by expert scoring through questionnaire survey. In the questionnaire, The importance of evaluation indexes in each training course sets "0-3" classes. If the relationship between them is small scoring 0 , has certain relation scoring 1 , has a close relation scoring 2, has a very important relationship scoring 3.Then normalized the data of questionnaire investigation according to flight course. The handled matrix names sample matrix. And then, put all the sample matrix weighted average, get the weight matrix .

trainer C172S, P2010, DA40 and SR20 for efficiency calculation. The time of each training course shows in 
table 1.Table 2 and table 3 show the value of aircraft scoring. evaluation indexes and comprehensive weight by expert

TABLE I. THE TRAINING TIME OF EACH COURSE

\begin{tabular}{|l|c|c|c|c|c|c|c|}
\hline \multirow{2}{*}{} & \multicolumn{7}{|c|}{ Training course } \\
\cline { 2 - 8 } & Course1 & Course 2 & Course 3 & Course 4 & Course 5 & Course 6 & Tot-al \\
\hline Time & 4 hours & 6 hours & 18 hours & 6 hours & 6 hours & 3 hours & 43 hours \\
\hline
\end{tabular}

TABLE II. THE VALUE OF PERFORMANCE INDEX

\begin{tabular}{|l|l|c|c|c|c|}
\hline \multirow{2}{*}{} & \multicolumn{4}{c|}{ Trainer } \\
\cline { 3 - 6 } & Take-off distance(ground roll)(m) & C172S & P2010 & DA40 & SR20 \\
\hline \multirow{5}{*}{$\begin{array}{c}\text { Performance } \\
\text { index }\end{array}$} & Take-off distance(50 foot obstacle)(m) & 293 & 245 & 352 & 409 \\
\cline { 2 - 6 } & landing distance(ground roll)(m) & 175 & 139 & 158 & 188 \\
\cline { 2 - 6 } & landing distance(50-foot obstacle)(m) & 232 & 113 & 281 & 313 \\
\cline { 2 - 6 } & Maximum rate of climb(m/s) & 3.71 & 5.10 & 5.75 & 4.20 \\
\cline { 2 - 6 } & Ceiling (km) & 4.27 & 4.57 & 5.00 & 5.33 \\
\cline { 2 - 6 } & Cruise speed of design(km/h) & 230.0 & 260.0 & 227.8 & 287.0 \\
\cline { 2 - 6 } & Maximum range(km) & 1185 & 1324 & 1341 & 1454 \\
\cline { 2 - 6 } & Maximum take-off weight(kg) & 1157 & 1199 & 1198 & 1361 \\
\hline
\end{tabular}

TABLE III. THE VALUE OF COMPREHENSIVE WEIGHT BY EXPERT

\begin{tabular}{|c|c|c|c|c|c|c|c|}
\hline & \multicolumn{6}{|c|}{ Training course } \\
\hline & & Course 1 & Course 2 & Course 3 & Course 4 & Course 5 & Course 6 \\
\hline \multirow{9}{*}{$\begin{array}{c}\text { Weight } \\
\text { Of } \\
\text { Performance } \\
\text { index }\end{array}$} & Take-off distance, ground roll(m) & 0.0963 & 0.1033 & 0.0997 & 0.1053 & 0.0969 & 0.1191 \\
\hline & $\begin{array}{l}\text { Take-off distance,50 foot } \\
\text { obstacle }(\mathrm{m})\end{array}$ & 0.1036 & 0.1033 & 0.2665 & 0.1053 & 0.0969 & 0.1082 \\
\hline & landing distance, ground roll(m) & 0.1036 & 0.1033 & 0.0997 & 0.1053 & 0.0969 & 0.1040 \\
\hline & $\begin{array}{l}\text { landing distance,50-foot } \\
\text { obstacle }(\mathrm{m})\end{array}$ & 0.0720 & 0.0533 & 0.0411 & 0.0553 & 0.0508 & 0.0952 \\
\hline & Maximum rate of $\operatorname{climb}(\mathrm{m} / \mathrm{s})$ & 0.1013 & 0.1029 & 0.1084 & 0.0962 & 0.1046 & 0.0997 \\
\hline & Ceiling (km) & 0.1013 & 0.0951 & 0.1036 & 0.0962 & 0.0969 & 0.1125 \\
\hline & Cruise speed of design $(\mathrm{km} / \mathrm{h})$ & 0.1408 & 0.1386 & 0.1036 & 0.1493 & 0.1551 & 0.1179 \\
\hline & Maximum range $(\mathrm{km})$ & 0.1384 & 0.1468 & 0.1384 & 0.1405 & 0.1551 & 0.1330 \\
\hline & Maximum take-off weight $(\mathrm{kg})$ & 0.1036 & 0.1033 & 0.0997 & 0.0966 & 0.0969 & 0.0973 \\
\hline
\end{tabular}

From table 1,we know

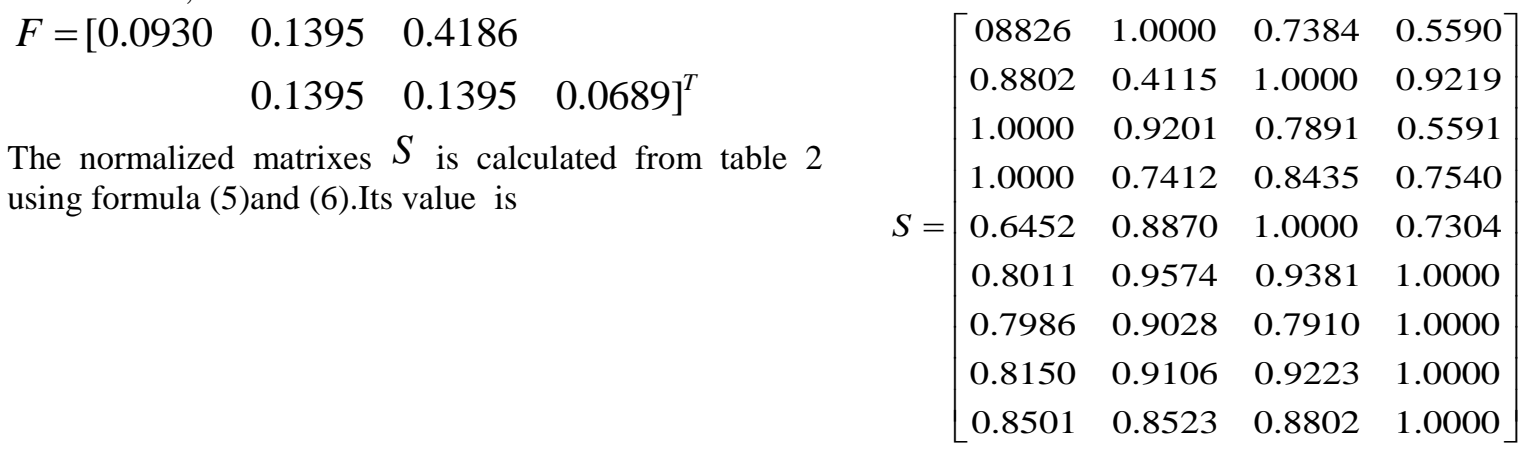


According to formula(2) and (3) ,the cross-efficiency vector could be calculated, its value is

$$
E=\operatorname{diag}(0.8827 \quad 0.6279 \quad 0.8047 \quad 0.6783)
$$

At last, put $S 、 E 、 W$ and $F$ to formula (1) and (4). The result is shown in table 4.

TABLE IV. THE RESULTS OF TWO KINDS OF MODEL

\begin{tabular}{|l|c|c|}
\hline & $\begin{array}{l}\text { Masefield-Burdak } \\
\text { model }\end{array}$ & $\begin{array}{l}\text { Based on DEA cross- } \\
\text { efficiency model }\end{array}$ \\
\hline C172S & 0.871 & 0.770 \\
\hline DA40 & 0.867 & 0.696 \\
\hline SR20 & 0.837 & 0.570 \\
\hline P2010 & 0.837 & 0.526 \\
\hline
\end{tabular}

Table 4 shows that for this pilot school' commercial single engine training, the $\mathrm{C} 172 \mathrm{~S}$ training effectiveness is the highest, followed by the DA40, SR20 and P2010.Results show that the trainer training effectiveness evaluation model based on DEA cross-efficiency is consistent with Masefield - Burdak model. Correctness of the model is verified. The results also shows more precision than Masefield - Burdak model.

\section{ACKNOWLEDGMENT}

China Aviation Industry Cooperative Innovation Project ( CXY2011MHDX30; Project supported by the fundamental research funds for the Central Universities (CY-1407)

\section{CONCLUSION}

This article discusses the Masefield-Burdak trainer training effectiveness evaluation model, and uses DEA cross-efficiency model to revise it, making up the shortage of it. When using revised model for evaluation, the benefit-type indexes of evaluation unit is used as cross efficiency model output indexes, cost-type indexes as input indexes. The Correctness of the model is verified, consistency with Masefield -Burdak model evaluation results, shows that the model is feasible.

\section{REFERENCES}

[1] [1] Ermanno Bazzocchi, "Military pilot training philosophy considerations on present and future trends "China Defense Science and Technology Information Center”, Dec,1988.

[2] [2] HUANG Jun, CAO Huaizhi,WU Wen-zheng. "Assessment of conceptual design for an advanced training aircraft using training efficiency". Chinese Journal of Aeronautics, vol.19 Sep. 1998,pp.70-73.

[3] [3] AI Jianliang, Ai Lingying, Li Zhiwen, “ On exploring method and software for evaluating effectiveness of military training aircraft". Journal of Northwestern Polytechnical University , Vol.21,Dec.2003,pp.696-698.

[4] [4]PAN Hongshan, He Wutao, "Characteristic cognition and development thought of training aircraft", trainer,Vol.3,Aug.2012,pp.28-30

[5] [5] LI Hang-hang, SONG Bi-feng, GAO Hong-jian, "Computation method improvement of military training plane effectiveness", Journal of Beijing University of Aeronautics and Astronautics,Vol.32,Jun,2006, pp.680-683.

[6] [6] GAO Min, AI Jian-liang, LI Zhi-wen, Deng Juan, WAN Jing, "On Exploring Method and Software for Evaluating Effectiveness of Military Training Aircraft",Chinese Journal of Aeronautics ,Vol.6,Aug.2009,pp.607-611.doi: 10.1016/S10009361(08)60148-X

[7] [7] WANG Xiao-hong, ZHAI Ai-mei, WANG Xue-feng, "Method formultiple-parameters evaluation modified by DEA model", Journal of Harbin Institute of Technology, Vol.41,Aug.2009,pp.103-106.

[8] [8] Charnes A, Cooper W W, Rhodes E, "Measuring the efficiency of decision making units", European Journal of Operational Research,Vol.2,Apr.1978,pp.429-444.

[9] [9] Sexton TR, Silkman RH, Hogan AJ,'Data envelopment analysis: critique and extensions. In: Silkman, RH (ED), Measuring Efficiency: An Assessment of Data Envelopment Analysis JosseyBass", San Francisco:Jossey-Bass,1986,pp.73-105.

[10] [10] SHU Wei-hua. "Research on Multi-index Comprehensive Evaluation Theory and Method", Xiamen Universit, 2000.

[11] [11] WU Jie, SHI Qin,Multi-index evaluation based on DEA method [J].System Engineering and Electronics, Vol.28,Oct.2006,pp.1541- 1543 